\title{
Asymmetric Biginelli-like reaction catalyzed by chiral TADDOL-derived phosphoric acid bearing two hydroxyl groups
}

\author{
Jianxin Guo ${ }^{1}$, Rui Zhang ${ }^{1}$, Zhongyou Yin ${ }^{1}$, Xiaoyun $\mathrm{Hu}^{1, *}$, Victor Borovkov ${ }^{1}$ \\ ${ }^{I}$ College of Chemistry and Materials Science, South-Central University for \\ Nationalities, Wuhan 430074, P. R. of China \\ Email: xyhu@mail.scuec.edu.cn
}

\begin{abstract}
Several new chiral TADDOL-derived phosphoric acids bearing two hydroxyl groups have been successfully synthesized via highly regioselective 2,3cyclosulfitation as asymmetric catalysts for Biginelli-like reaction. The obtained results clearly demonstrated that these catalysts are able to effectively catalyze both types of the reactions with good to excellent enantioselectivities. A control experiment indicated that two hydroxyl groups are indispensable for high enantioselectivity of the Biginellilike reaction.
\end{abstract}




\section{Introduction}

Dihydropyrimidinethiones (DHPMs), which have important biological activities, are an important class of heterocyclic compounds. They feature in a large number of natural and unnatural compounds with important biological activities and serve as key intermediates for the synthesis of many kinds of drug candidates. During the last decade, chiral DHPMs derivatives have shown important pharmacological properties such as antiviral $^{1,2}$, antitumour ${ }^{3}$, antibacterial, anti-inflammatory ${ }^{4}$, and antihypertensive ${ }^{5}$ activities. However, the individual enantiomers of DHPMs have been found to exhibit different or even opposite pharmaceutical activities. ${ }^{6-8}$ For example, $(S)$-monastrol is 15-fold more powerful in the inhibition of Eg 5 ATPase than $(R)$-monastrol. ${ }^{9}(S)-L$ 771688 (3) is a more powerful and selective $\alpha_{1 \mathrm{a}}$ receptor antagonist for the treatment of benign prostatic hyperplasia $(\mathrm{BPH})$ than $(R)$-enantiomer. ${ }^{10}$ As more reports on the enantiospecific biological activity are identified, developing an efficient and reliable asymmetric synthesis of chiral DHPMs becomes ever more valuable.

Multicomponent Biginelli and Biginelli-like reactions of aldehydes, urea/thiourea, and enolizable carbonyls are very efficient tools to prepared pharmacological DHPMs. ${ }^{11}$ Though Biginelli reaction was firstly recognized over a century ago ${ }^{12}$, little attention is substantially given to asymmetric catalytic Biginelli reaction. Until 2013, Juaristi and Muñoz-Muñiz reported asymmetric catalytic the Biginelli reaction of benzaldehyde, urea, and methyl acetoacetate using a chiral amide with $\mathrm{CeCl}_{3}$, however, only $40 \%$ ee was obtained. ${ }^{13}$ Zhu reported the first efficient asymmetric catalytic Biginelli reaction with a chiral ytterbium catalyst to provide excellent enantioselectivities up to $>99 \%$ ee. ${ }^{14}$ Gong reported the first organocatalytic Biginelli reaction using BINOL derived chiral phosphoric acids as catalysts, furnishing DHPMs with up to $97 \%$ ee. ${ }^{15,16}$ Recently, our group reported chiral phosphoric acids bearing dihydroxyl groups derived from natural tartaric acid catalyzed asymmetric Biginelli reaction, up to $99 \%$ ee was obtained. ${ }^{17}$ This type of phosphoric acids feature with easy preparation and low-cost. To further expand a broad scope of enolizable ketones for Biginelli-like reactions, Biginelli-like reaction of aldehydes, benzylthiourea and 
cyclohexanone catalyzed by chiral phosphoric acids bearing dihydroxyl groups were explored in this work. Herein we report the full results of our studies, which provided a highly efficient method to access DHPMs with structural diversity and excellent levels of enantioselectivity (up to $95 \%$ ee).

\section{Results and Discussion}

Enantiomerically pure 1,1,4,4-tetrasubstituted butanetetraols 1 are parent compounds of TADDOLs, which conventionally obtained from chiral tartaric acids. The hydroxyl group composition of 1 ensures their diverse reactivity. In 2010, our group established a convenient accesses to 1 via direct alkylation of diethyl tartrates with $\mathrm{RMgBr}^{18}$ with further modifications involving highly regioselective 1,4 -cycloetherization ${ }^{19}$, 1,3-

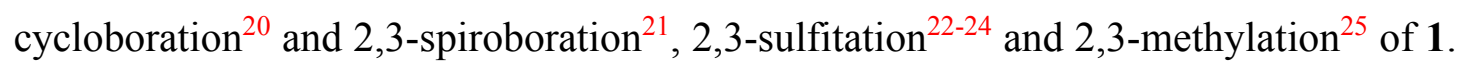
Therefore, the strategy for the catalyst's preparation was based on established regioselective 2,3-sulfitation reaction of $\mathbf{1}$ and ready hydrolysis of the corresponding intermediate in $\mathrm{NaOH}$ solution to yield several new chiral phosphoric acids $(R, R)-\mathbf{3}$ bearing free dihydroxyl groups at 2- and 3-positions, as shown in Scheme 1.

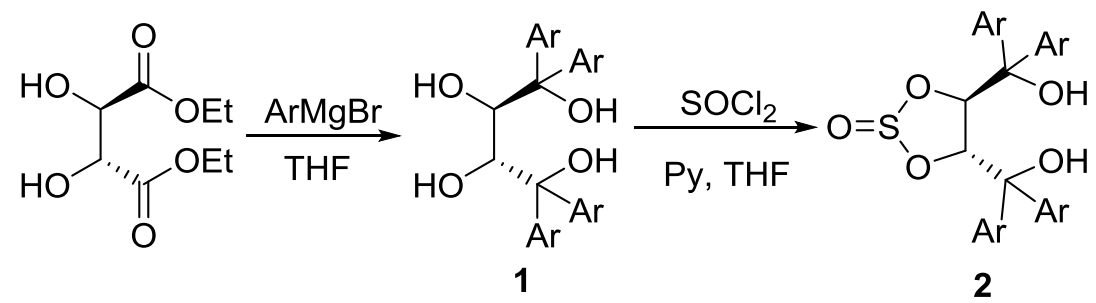

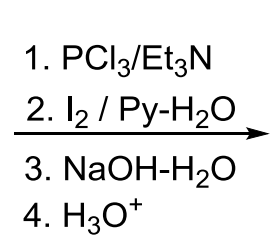

1. $\mathrm{PCl}_{3} / \mathrm{Et}_{3} \mathrm{~N}$

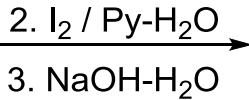

4. $\mathrm{H}_{3} \mathrm{O}^{+}$ 3a, $\mathrm{Ar}=\mathrm{Ph}$

3b, $\mathrm{Ar}=4-\mathrm{CH}_{3} \mathrm{C}_{6} \mathrm{H}_{4}$

3c, $\mathrm{Ar}=4-{ }^{t} \mathrm{BuC}_{6} \mathrm{H}_{4}$

$3 d, \mathrm{Ar}=4-\mathrm{FC}_{6} \mathrm{H}_{4}$

3e, $\mathrm{Ar}=4-\mathrm{CF}_{3} \mathrm{C}_{6} \mathrm{H}_{4}$

3f, $\mathrm{Ar}=3,5-\left(\mathrm{CF}_{3}\right)_{2} \mathrm{C}_{6} \mathrm{H}_{3}$

Scheme 1 Synthesis of chiral phosphoric acid 3a-3f.

The synthesized chiral phosphoric acids 3 were examined to catalyze asymmetric Biginelli-like reaction. Firstly, the reaction of benzenaldehyde, cyclohexanone and $\mathrm{N}$ benzyl thiourea was set as the reaction model. As shown in table 1, screening of catalysts indicated that all the chiral phosphoric acids $\mathbf{3}$ could promote this reaction 
(entries 1-6) and 3a had the best performance (89\% ee) in toluene. To our pleasure, screening of solvent showed that the aimed product could be obtained with $95 \%$ ee catalyzed by $3 \mathbf{a}$ in $\mathrm{CHCl}_{3}$ (entry 9). Reaction temperature also was investigated (entries 14,15). Based on these results, the optimal conditions were as following: $10 \mathrm{~mol} \% 3 \mathrm{a}$ as the catalyst, $\mathrm{CHCl}_{3}$ as the reaction solvent at $50{ }^{\circ} \mathrm{C}$ for 6 days.

Table 1 Optimization of reaction conditions. ${ }^{\mathrm{a}}$

\begin{tabular}{cccccc} 
& & & \\
\hline
\end{tabular}

${ }^{a}$ Reaction was carried out on a $0.2 \mathrm{mmol}$ scale, the ratio of $\mathbf{4 a} / \mathrm{N}$-benzyl thiourea/cyclohexanone was $1.5 / 1.0 / 5.0$ and $10 \mathrm{~mol} \%$ of $3{ }^{b}$ Isolated yields. ${ }^{c}$ ee was determined by HPLC.

With the optimal conditions in hand, the scope of aromatic aldehydes 5 was explored. As shown in table 2, a range of aromatic aldehydes gave aimed products in high yields 
with moderate to excellent enantioselectivities. In particular, benzaldehyde and 3bromobenzaldehyde gave 7 in $95 \%$ and $91 \%$ (entries 1 and 3). While the introduction of electron-withdrawing group such as nitro resulted in declining of stereoselectivity (entry 8).

Table 2 Results of the Biginelli-like reaction catalyzed by $\mathbf{3 a} .^{\mathrm{a}}$

\begin{tabular}{ccclcc}
\hline & & & & e.e. $\%$ \\
\hline entry & $\mathrm{R}$ & $\mathrm{T} /{ }^{\circ} \mathrm{C}$ & solvent & \\
\hline 1 & $\mathrm{H}$ & 50 & $\mathrm{CHCl}_{3}$ & 85 & 95 \\
2 & $2-\mathrm{Br}$ & 50 & $\mathrm{CHCl}_{3}$ & 86 & 77 \\
3 & $3-\mathrm{Br}$ & 50 & $\mathrm{CHCl}_{3}$ & 83 & 91 \\
4 & $4-\mathrm{Br}$ & 50 & $\mathrm{CHCl}_{3}$ & 90 & 87 \\
5 & $4-\mathrm{CH}_{3}$ & 50 & $\mathrm{CHCl}_{3}$ & 88 & 80 \\
6 & $4-\mathrm{CH}_{3} \mathrm{O}$ & 50 & $\mathrm{CHCl}_{3}$ & 85 & 83 \\
7 & $4-\mathrm{F}$ & 50 & $\mathrm{CHCl}_{3}$ & 89 & 73 \\
8 & $4-\mathrm{NO}_{2}$ & 50 & $\mathrm{CHCl}_{3}$ & 79 & 42 \\
\hline
\end{tabular}

${ }^{a}$ Reaction was carried out on a $0.2 \mathrm{mmol}$ scale, the ratio of $\mathbf{4} / \mathrm{N}$-benzyl thiourea/cyclohexanone was $1.5 / 1.0 / 5.0$ and $10 \mathrm{~mol} \%$ of $3 \mathbf{a}^{b}{ }^{b}$ Isolated yields. ${ }^{c}$ ee was determined by HPLC.

To confirm if the two hydroxyl groups in chiral phosphoric acids $\mathbf{3}$ played a crucial role in the asymmetric catalyzed Biginelli-like reaction. Chiral phosphoric acid $\mathbf{3 g}$ was designed and synthesized. As shown in Scheme 2, $(2 R, 3 R)-\mathbf{1}$ underwent highly regioselective 2,3-dimethylation with $\mathrm{NaH} / \mathrm{MeI}$ to give $(2 R, 3 R)-\mathbf{6}$, then the corresponding chiral phosphoric acid $\mathbf{3 g}$ was synthesized according to previous procedure.

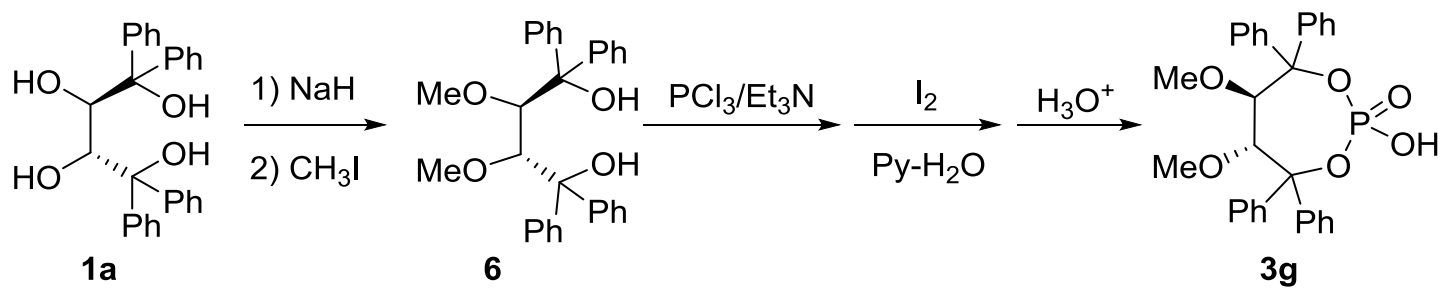

Scheme 2 Synthesis of chiral phosphoric acid $\mathbf{3 g}$.

Then the synthesized $\mathbf{3 g}$ was applied to catalyze the model reaction of benzenaldehyde, cyclohexanone and $N$-benzyl thiourea under the above optimal conditions. As shown in Scheme 3, the aimed product was obtained in $60 \%$ yield with 
$7 \%$ ee. This controlled experiment clearly indicated that the two hydroxyl groups in $\mathbf{3 g}$ did have a very important influence on the stereoselectivity of Biginelli-like reaction.

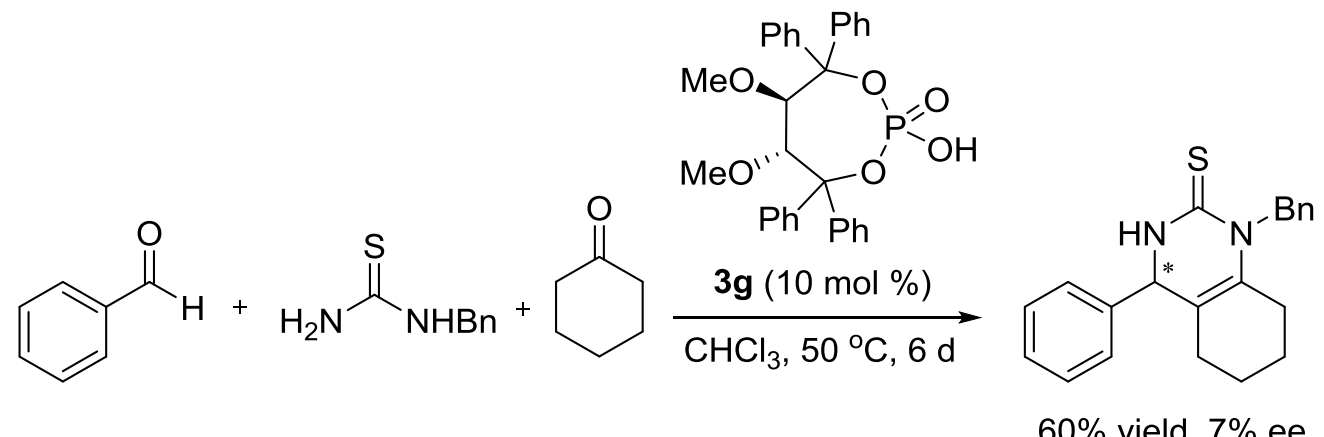

Scheme 3 The controlled experiment.

Based on these results, a plausible transition state structure was proposed. As shown in figure 1, the chiral phosphoric acid catalyst activated the imine, which was formed by a condensation of benzenealdehyde with N-benzyl thiourea. The two hydroxyl groups formed a five-numbered intramolecularand a seven-numbered intermolecular $\mathrm{H}$ bond with the enolizable ketone, respectively. This rigid transition state structure is favorable for stereoselective attack of enol on imine. Once the two hydroxyl groups were etherified, the enolizable ketone was activated by the oxygen atom of phosphoryl, loss of rigid structure would lead to low enantioselectivity.

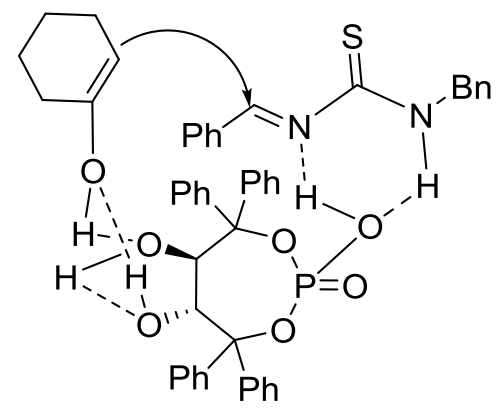

Figure 1 The proposed activation model and reaction pathways of the stereogenic step in the phosphoric acid 3a-catalyzed Biginelli-like reaction.

\section{Conclusion}

In summary, we have designed and synthesized several novel phosphoric acids carrying dihydroxyls based on highly regio-selecive transformation of chiral 1,1,4,4tetrasubstituted butanetetraols. And the phosphoric acids were applied to asymmetric 
catalysis of Biginelli-like reactions. The results demonstrated that this type of chiral phosphoric acids could effectively promote Biginelli-like reaction and furnish moderate to excellent enantioselectivities. Controlled experiment indicated that the two hydroxyls in the phosphoric acid backbone played a pivotal role in improving the stereoselectivity of Biginelli-like reaction. Based on the controlled experiment, a plausible activation model and reaction pathways of the stereogenic step in the phosphoric acid 3a-catalyzed Biginelli-like reaction was proposed.

\section{References}

1. Kappe, C. O. Eur. J. Med. Chem., 2000, 35, 1043.

2. Aron, Z.D.; Overman, L.E. J. Am. Chem. Soc. 2005, 127, 3380.

3. Kappe, C. O.; Kumar, D.; Varma, R. S. Synthesis, 1999, 1799.

4. Arnold, M. A.; Day, K. A.; Duron, S. G.; Gin, D. Y. J. Am. Chem. Soc. 2006, 128, 13255.

5. Makarieva, T. N.; Tabakmaher, K. M.; Guzii, A. G.; Denisenko, V. A.; Dmitrenok, P. S.; Shubina, L. K.; Stonik, V. A. J. Nat. Prod. 2011, 74, 1952.

6. Rovnyak, G. C.; Kimball, S. D.; Beyer, B.; Cucinotta, G.; DiMarco, J. D.; Gougoutas, J.; Hedberg, A.; Malley, M.; McCarthy, J. P.; Zhang, R.; Moreland, S. J. Med. Chem. 1995, 38, 119.

7. Mayer, T. U.; Kapoor, T. M.; Haggarty, S. J.; King, R. W.; Schreiber, S. L.; Mitchison, T. J. Science 1999, 286, 971.

8. Kappe, C. O. In Multicomponent Reactions; Zhu, J., Bienayme, H., Eds.; WileyVCH: Weinheim, 2005; p 95.

9. DeBonis, S.; Simorre, J. P.; Crevel, I.; Lebeau, L.; Skoufias, D. A.; Blangy, A.; Ebel, C.; Gans, P.; Cross, R.; Hackney, D. D.; Wade, R. H.; Kozielski, F. Biochemistry 2003, 42, 338.

10. Barrow, J. C.; et al. J. Med. Chem. 2000, 43, 2703.

11. Nagarajaiah, H.; Mukhopadhyay, A.; Moorthy, J. N. Tetrahedron Lett. 2016, 57, 5135.

12. Biginelli, P. Gazz. Chim. Ital. 1893, 23, 360.

13. Muño-Muñiz, O.; Juaristi, E. ArkiVoc 2003, xi, 16.

14. Huang, Y.; Yang, F.; Zhu, J. J. Am. Chem. Soc. 2005, 127, 16386.

15. Chen, X. H.; Xu, X. Y.; Liu, H.; Cun, L. F.; Gong, L. Z. J. Am. Chem. Soc. 2006, 128, 14802.

16. Li, N.; Chen, X. H.; Song, J.; Luo, S. W.; Fan, W. Gong, L. Z. J. Am. Chem. Soc. 2009, 131, 
15301.

17. Hu, X. Y.; Zhang, R.; Xie, J. S.; Zhou, Z. Q.; Shan, Z. X. Tetrahedron: Asymmetry, 2017, 28, 69.

18. Shan, Z. X.; Hu, X. Y.; Zhou, Y.; Peng, X. T.; Li, Z. Helv. Chim. Acta 2010, 93, 497.

19. Hu, X. Y.; Shan, Z. X.; Peng, X. T.; Li, Z. Tetrahedron: Asymmetry 2009, 20, 2474.

20. Shan, Z. X.; Hu, X. Y.; Zhou, Y.; Peng, X. T.; Yi, J. Tetrahedron: Asymmetry 2009, 20, 1445.

21. Hu, X. Y.; Shan, Z. X.; Song, S. J. Tetrahedron: Asymmetry 2014, 25, 503.

22. Hu, X. Y.; Shan, Z. X.; Soloshonok, V. A. Cryst. Growth Des. 2012, 12, 33.

23. Xie, J. S.; Hu, X. Y.; Shan, Z. X.; Zhou, Z. Q. Aust. J. Chem. 2015, 68, 995.

24. Hu, X. Y.; Chen, D. Z.; Lan, J. R.; Shan, Z. X. Phosphorus, Sulfur, and Silicon and the Related Elements 2016, 191, 1291.

25. Hu, X. Y.; Yin, Z. Y.; Tang, Y. L. Wu, L. M. Journal of South-Central University for Nationalities(Nat . Sci . Edition) 2019, 38, 22. 